\title{
Broad, intense, quiescent beam of singly charged metal ions obtained by extraction from self-sputtering plasma far above the runaway threshold
}

\author{
André Anders ${ }^{1 *}$ and Efim Oks ${ }^{2}$ \\ ${ }^{1}$ Lawrence Berkeley National Laboratory, 1 Cyclotron Road, Berkeley, California 94720, \\ USA \\ ${ }^{2}$ High Current Electronics Institute, Russian Academy of Sciences, 2/3 Academichesky \\ Ave., Tomsk 634055, Russia
}

May 19, 2009

\section{ACKNOWLEDGMENT}

This work was supported by the U.S. Department of Energy, Initiatives for Proliferation Prevention, under Contract No. DE-AC02-05CH11231 with the Lawrence Berkeley National Laboratory.

\section{DISCLAIMER}

This document was prepared as an account of work sponsored by the United States Government. While this document is believed to contain correct information, neither the United States Government nor any agency thereof, nor The Regents of the University of California, nor any of their employees, makes any warranty, express or implied, or assumes any legal responsibility for the accuracy, completeness, or usefulness of any information, apparatus, product, or process disclosed, or represents that its use would not infringe privately owned rights. Reference herein to any specific commercial product, process, or service by its trade name, trademark, manufacturer, or otherwise, does not necessarily constitute or imply its endorsement, recommendation, or favoring by the United States Government or any agency thereof, or The Regents of the University of California. The views and opinions of authors expressed herein do not necessarily state or reflect those of the United States Government or any agency thereof or The Regents of the University of California.

\footnotetext{
* Author to whom correspondence should be submitted. Electronic mail aanders@lbl.gov
} 


\title{
Broad, intense, quiescent beam of singly charged metal ions obtained by extraction from self-sputtering plasma far above the runaway threshold
}

\author{
André Anders ${ }^{1 *}$ and Efim Oks ${ }^{2}$ \\ ${ }^{1}$ Lawrence Berkeley National Laboratory, 1 Cyclotron Road, Berkeley, California 94720, \\ USA \\ ${ }^{2}$ High Current Electronics Institute, Russian Academy of Sciences, 2/3 Academichesky \\ Ave., Tomsk 634055, Russia
}

\begin{abstract}
Dense metal plasmas obtained by self-sputtering far above the runway threshold are well suited to generate intense quiescent ion beams. The dilemma of high current density and charge state purity can be solved when using target materials of low surface binding energy by utilizing non-resonant exchange reactions before ion extraction. Space-chargelimited quiescent beams of $\mathrm{Cu}^{+}, \mathrm{Zn}^{+}$, and $\mathrm{Bi}^{+}$with $\sim 10 \mathrm{~mA} / \mathrm{cm}^{2}$ have been obtained through multi-aperture gridded ion extraction up to $45 \mathrm{kV}$ from self-sputtering plasmas.
\end{abstract}

PACS: $52.59 . \mathrm{Bi}, 81.15 . \mathrm{Cd}, 52.80 . \mathrm{Vp}, 52.25 . \mathrm{Ya}$

\footnotetext{
*Author to whom correspondence should be submitted. Electronic mail aanders@lbl.gov
} 


\section{INTRODUCTION}

For many applications of ion beams, it is highly desirable to have a stable, reliable source of ions with high current density and low beam divergence, i.e., high brightness and low emittance. Additionally, beams should be of low noise and high purity in terms of elemental composition and ion charge states. It is difficult to generate intense beams of heavy ions containing only one charge state because, on the one hand, high power density is required to generate the dense plasma, and on the other hand, the high power density will promote the generation of doubly or even higher charged ions ${ }^{1,2}$.

Considering broad beam sources of metal ions, the vacuum arc ion source ${ }^{1}$ comes to mind. It can deliver high beam current, however, such source is also known for a rather broad distribution of ion charge states and large beam noise. Fluctuations of the plasma density caused by explosive plasma formation ${ }^{3}$ necessarily produces changes at the plasma meniscus, the boundary of plasma in an extraction system ${ }^{1,4}$, followed by fluctuations of the beam emittance. To mitigate this issue, it is common to "define" the emitting surface by a fine mesh placed on the plasma grid of the extractor system.

In this contribution we will show that this fundamental dilemma of high power density and the presence of multiple charge states can be overcome in an elegant manner for a certain class of metals by using sustained self-sputtering plasma far from the runaway threshold. We will demonstrate that high purity in elemental and charge state composition can be obtained with high current density and low noise, and we will argue that such source could be readily scaled to very large cross section with good beam uniformity. 


\section{SOME THEORETICAL CONSIDERATIONS OF ION BEAMS AND SELF-}

\section{SPUTTERING PLASMAS}

An ion source generally consists of an ion generator, either a field emitter or plasma-producing discharge, coupled to an ion extraction and acceleration system. Multiple-aperture three-grid systems (acceleration-deceleration) are commonly used to obtain a set of beamlets which merge to form a broad beam as the beam propagates ${ }^{1,4,5}$.

The quality of the beam (high brightness, low emittance) largely depends on the properties of the plasma, specifically on the fluctuation of the plasma density and transverse ion temperature. It is generally desirable to work with dense, quiescent plasmas because the spreading of the beam due to space charge can be offset by optimizing the shape of the concave meniscus of the plasma boundary at the extracting aperture. Spreading by space charge can be quantified by the perveance ${ }^{4}$,

$$
P=I_{i} / V_{\text {accel }}^{3 / 2},
$$

or normalized perveance, also known as poissance, $P_{n}=P / \chi$, where $I_{i}$ is the ion current transported in one aperture, $V_{\text {accel }}$ is the accelerating voltage, and

$$
\chi=\frac{4}{9} \varepsilon_{0}\left(\frac{2 e}{m_{i}}\right)^{1 / 2}
$$

is the Child factor which depends on the ion mass $m_{i} ; \varepsilon_{0}$ is the permittivity of free space and $e$ is the elementary charge. The maximum current is given by the well-known Child law

$$
j_{i}=\chi V_{\text {accel }}^{3 / 2} / d^{2}
$$

where $d$ is the grid spacing ${ }^{4}$. Well collimated beams have a poissance less than unity, preferably $\sim 0.1-0.2$. 
High power impulse magnetron sputtering (HiPIMS) discharges generate dense plasmas $^{6-9}$. Here we follow the ideas that (i) the plasma can be completely metal dominated when operated with sustained self-sputtering, (ii) the charge state distribution is dominated by singly charged ions due to charge exchange reactions, and (iii) the discharge parameters may be selected such that fluctuations are minimal.

Self-sputtering ${ }^{10}$ can run away for target materials of low surface binding energy, like copper, meaning the that self-sputtering amplifies itself when the self-sputtering parameter $\Pi$ exceeds unity ${ }^{9,11,12}$,

$$
\Pi \equiv \alpha \beta \gamma_{S S}>1
$$

where $\alpha$ is the probability that a sputtered atoms is ionized, $\beta$ is the probability that the newly formed ion returns to the target, and $\gamma_{s s}$ is the self-sputtering yield. Runaway is slowed by (a) the increasing flux of sputtered atoms that cools the plasma electrons ( $\alpha$ decreases), and (b) increasing ion "losses," i.e., flux of ions not returning to the target ( $\beta$ decreases). As a desirable side effect, the latter implies that more ions are available for deposition ${ }^{9}$ or extraction. The discharge settles at new equilibrium characterized by $\Pi=1$, which typically happens on a timescale of $10 \mu \mathrm{s}$ and at target power densities of $\sim 1 \mathrm{~kW} / \mathrm{cm}^{2}$ or greater.

It is not trivial to expect that the plasma will exhibit a charge state distribution function dominated by a single charge state at very high power densities. Indeed, doubly and even higher charged ions have been detected in some HIPIMS plasmas ${ }^{12-15}$. They have an important function in enabling sufficient plasma heating by creating secondary electrons ${ }^{16}$. However, the secondary electron yield of singly charged metal ions is extremely small ${ }^{17}$. Baragiola's empirical expression for the secondary electron yield ${ }^{18}$, 


$$
\gamma_{S E}=0.032\left(0.78 E_{p o t}-2 \phi\right),
$$

requires $0.78 E_{p o t}>2 \phi$ in order for any potential emission to occur. A closer look at the work functions and first ionization energies of metals ${ }^{19}$ shows that the condition (5) is not fulfilled for any singly charged ion of any metal. The consequence is that, for pure metal plasma, at least a small percentage of ions hitting the target needs to be doubly charged ${ }^{16}$.

A large sputtering yield, enabling a large flux of neutral atoms, may also be utilized to achieve the goal of a charge-state-pure ion beam via annihilation of the higher charge states before they reach the extractor by non-resonant charge exchange reactions

$$
\mathrm{M}^{Q+}+\mathrm{M} \rightarrow \mathrm{M}^{(Q-1)+}+\mathrm{M}^{+}+\Delta E, \quad Q>1,
$$

where $\mathrm{M}$ stands for the neutral atom and $\mathrm{M}^{Q+}$ represents the $Q$-fold charged ion of the same metal. $\Delta E=\sum_{\text {before }} E_{\text {ion }}-\sum_{\text {affer }} E_{\text {ion }}$ is the energy defect, i.e. the difference of the ionization energies of the colliding particles before and after electron transfer. For the most relevant case of $Q=2$ we have

$$
\Delta E=\left[\left(E_{0 \rightarrow 1}+E_{1 \rightarrow 2}\right)+0\right]-\left[E_{0 \rightarrow 1}+E_{0 \rightarrow 1}\right]=E_{1 \rightarrow 2}-E_{0 \rightarrow 1},
$$

and the results are listed in Table I. The cross section is generally very large ${ }^{20,21}$, typically $\geq 4 \times 10^{-19} \mathrm{~m}^{2}$, with the $\mathrm{M}^{(\mathrm{Q}-1)+}$ ion usually highly excited to provide quasiresonant conditions ${ }^{22}$. For $\mathrm{Cu}$ and $\mathrm{Bi}$, the energy defect is larger than the first ionization energy and therefore both collision products need to be in the excited state to satisfy energy conservation. All reactions of the type (6) produce singly ionized ions from neutrals, thereby increasing the number of singly charged ions at the extractor system while reducing the number of multiply charged. 
The current at the target is composed of ion current and secondary electron current, $I_{\text {target }}=I_{i}+I_{S E}=I_{i}\left(1+\gamma_{S E}\right)$, with $\gamma_{S E} \ll 1$ and hence $I_{\text {target }} \approx I_{i}$. The flux of metal atoms by self-sputtering is $F_{a}=\gamma_{S S}\left(E_{i}\right) j_{i} / e$. Neglecting for a moment collisions, this flux can be used to determine the initial density of sputtered atoms,

$$
n_{a} \approx F_{a} / \overline{v_{a}}=F_{a} / \sqrt{2 \overline{E_{a}} / m_{a}},
$$

where $\overline{E_{a}}$ is the average energy of the sputtered atoms. Considering the case of copper and assuming $E_{i}=600 \mathrm{eV}$ and $j_{i} \approx I_{i} / A_{\text {target }} \sim 5 \mathrm{~A} / \mathrm{cm}^{2}$, one obtains from TRIM calculations ${ }^{23} \gamma_{s S}=2.4$ and $\overline{E_{a}}=12 \mathrm{eV}$, leading to $n_{a} \approx 1.4 \times 10^{20} \mathrm{~m}^{-3}$. Hence, the initial mean free path for charge exchange, $\lambda=\left(n_{a} \sigma_{C E}\right)^{-1}$, is therefore about $1.8 \mathrm{~cm}$ or less.

Some of the initially sputtered atoms will collide with the background gas and lose kinetic energy. As a consequence, the gas density will be reduced (rarefaction ${ }^{24}$ ) but the density of sputtered atoms will be increased, an effect well known and utilized in ionized physical vapor deposition (i-PVD) ${ }^{25}$. As metal ions are formed near the target, a large portion will be accelerated to the target, and thereby momentum is provided towards the target via resonant ion-atom collisions

$$
\tilde{\mathrm{M}}^{+}+\mathrm{M} \rightarrow \tilde{\mathrm{M}}+\mathrm{M}^{+},
$$

where the tilde marks one of the colliding particles. The cross sections for resonant charge exchange are well studied; data for the energy range of 1-10 eV of kinetic energy in the center-of-mass reference frame are given in Table $\mathrm{I}^{26}$. As the charge exchange process evolves, slowing of the sputtered flux becomes stronger, the metal density increases, and this positive feedback promotes further metal ionization because the sputtered atom resides longer in the zone where magnetized electrons cause impact 
ionization collisions. The mean free path of sputtered particles is more likely to be on the millimeter scale, or even less, and therefore the character of the metal flux completely changes from ballistic in the initial phase of the discharge to diffusive in the sustained self-sputtering phase. This means that in the equilibrium phase far above the selfsputtering threshold, the sputtered atoms are likely to change several times from atom to singly charged ion and back, and very few multiply charged ions should be expected.

\section{EXPERIMENTAL}

The experimental results reported here were obtained with a 2 inch $(5 \mathrm{~cm})$ planar magnetron fed by a $3 \Omega, 250 \mu$ s pulse-forming-network (PFN) charged up to $1000 \mathrm{~V}$. The whole system was electrically isolated from ground and operated a potential of up to $45 \mathrm{kV}$ above ground to allow extraction of ions from the self-sputtering plasma. The system is similar to what was used for recent time-of-flight (TOF) spectrometer experiments $^{27}$. Here, however, the whole grid with 163 holes of $4.7 \mathrm{~mm}$ diameter each was utilized. A fine mesh with $60 \%$ transmittance was spot-welded to the plasma-facing side of the first grid, resulting in a nominal extraction area of $17 \mathrm{~cm}^{2}$. Ion extraction was realized using an unsophisticated (non-Pierce) multi-aperture three-grid accelerationdeceleration extraction system in $4 \mathrm{~cm}$ distance from the target, with the acceleration grid distance of $1.28 \mathrm{~cm}$. The grids were also used to limit conductance between the discharge zone and the main chamber, the latter being pumped by a $1500 \mathrm{l} / \mathrm{s}$ cryogenic pump. In this way it was ensured that a sufficiently high initial gas pressure $(\sim 0.2 \mathrm{~Pa})$ and later high plasma density can exist near the target while the mean free path in the time-of-flight spectrometer is larger than the spectrometer's length. 
The beam current profile was measured with a Faraday cup (FC, aperture area $0.237 \mathrm{~cm}^{2}$ ) inserted into the beam $0.5 \mathrm{~m}$ downstream of the extractor grids via a linear motion feedthrough. The total beam current was determined by integrating over the beam profile, $I_{i, \text { total }}=2 \pi \int_{0}^{r_{\max }} i(r) r d r$. Alternatively, a second FC with a much larger aperture of $20 \mathrm{~cm}^{2}$ could be inserted to monitor the intensity of the central part of the beam. Each of the FCs had a transverse permanent-magnet field to suppress secondary electrons. With the FCs removed from the beam path, the beam arrived at the TOF's gating plates and was deflected toward the TOF's Faraday cup when a gate pulse of $2 \mathrm{kV}$, 200 ns was applied. Further details can be found in $\operatorname{ref}^{27,28}$.

\section{RESULTS}

Figures 1 and 2 are examples of beam pulses in time and space. The beam has a central plateau, approximately extending to the outer radius of target racetrack. At larger distances from the axis, the beam current falls and one can that the decrease is even stronger outside the extractor radius. This type of profile could be interpreted that the plasma density at the edge of multi-aperture grid is less than in the center portion and/or that the beam exhibit a divergence of about $0.8 \mathrm{mrad}$. The increase of the beam current with increasing extraction voltage shows that the beam is space charge limited, as opposed to limited by the supply of ions, however, the poissance decreases as the extraction voltage is increased. The total ion current was very close to the calculated Child-Langmuir limit. The highest ion current observed was about $300 \mathrm{~mA}$ for copper for an extractor voltage of $45 \mathrm{kV}$ and a discharge current of $65 \mathrm{~A}$. We should recall that extracting ions in such wide range of extraction voltage is only possible by the use the 
mesh, which stabilized the emitting surface. To produce a higher quality beam, though, one needs to make use of a Pierce-type extractor utilizing optimized meniscus shape and poissance.

The TOF data confirmed that the plasma is dominated by singly charged ions, especially after the initial transient phase when doubly charged ions are still observed in significant quantities. This is illustrated in Fig. 3 for the copper and bismuth. Almost identical results were obtained for zinc, which is not further shown for space reasons. Steady-state is reached about $50 \mu$ s after the start of the current pulse. Single charged copper ions are already dominant after $25 \mu$ s, and in steady-state they comprise more than $95 \%$ of all ions. It is conceivable that this percentage could be even further increased by eliminating the gas component altogether by using "gasless" sputtering, where pulses are initiated by other means such as a short vacuum arc pulse ${ }^{29}$.

The goal of a low noise, almost pure metal ion beam of single charge state is thus demonstrated. Such ion beam based on self-sputtering plasma can be elegantly contrasted to a conventional metal ion beam from a vacuum arc ion source, up to now the most prolific metal ion source, by picking a pulse event that features both self-sputtering and arcing. Fig. 4 displays such event in which arcing onset accidentally happened in the middle of the pulse discharge pulse. A charging voltage pulse of $920 \mathrm{~V}$ was applied, and the current rose about $45 \mu$ s later, reaching approximate steady-state of $80 \mathrm{~A}$ within 50 $\mu \mathrm{s}$, at which time the burning voltage was about $650 \mathrm{~V}$. This is the quiescent magnetron discharge based on sustained copper self-sputtering. Suddenly, at $t=180 \mu \mathrm{s}$, arcing set in, characterized by a sharp drop of the burning voltage and an increase in the discharge current. The system switched to conditions comparable to those of conventional vacuum 
arc ion sources ${ }^{30}$, where metal plasma with a broad charge state distribution is produced at non-stationary cathode spots ${ }^{3}$. In our example, the current peaked at $260 \mathrm{~A}$. The voltage is noisy and less than $100 \mathrm{~V}$, which is higher than in a conventional vacuum $\operatorname{arc}^{31}$ due to the magnetic field structure $e^{32,33}$.

Before arcing, in the sustained self-sputtering phase, the power was $52 \mathrm{~kW}$, corresponding to a nominal average target power density of $2.6 \mathrm{~kW} / \mathrm{cm}^{2}$; though it is more physical to not consider the total target area but the active or "race track" area, which is about $8 \mathrm{~cm}^{2}$, leading to $6.5 \mathrm{~kW} / \mathrm{cm}^{2}$. In the arc phase, power dissipation drops sharply (due to the sharp voltage drop) and then shows a transient peak (due to the current rise) of about $25 \mathrm{~kW}$. Regardless of this total power, the power density at the very small, nonstationary cathode spots is about $10^{5}$ times greater than the characteristic target power density of sustained self-sputtering, and therefore it is not too surprising that the self-sputtering processes are quiescent, whereas the explosive cathode spot phenomena cause large, fractal fluctuations $s^{3,34}$ and produce multiply charged ions ${ }^{2,30}$.

Finally, let us consider the scalability of a self-sputtering ion source. In terms of intensity scaling it is not different than any other ion source except that, as long as discharge conditions are chosen that do not promote plasma instabilities, the quiescent nature makes it easier compared to the vacuum ion source. Due to the high burning voltage, the power dissipation is high, and therefore self-sputtering plasma far above the runaway threshold can deliver even greater ion fluxes than the vacuum $\operatorname{arc}^{9}$ at comparable current. The self-sputtering ion source may surpass the vacuum arc ion source also in terms of broad-beam scaling because it has been shown that HIPIMS and the related self-sputtering processes can be done on much larger targets ${ }^{13}$. Magnetrons 
come in circular, elongated, or other shapes, and therefore it is straightforward to envision broad beams of circular or "linear" cross section.

\section{SUMMARY AND CONCLUSIONS}

In summary, we have shown that the quiescent plasma obtained via sustained selfsputtering, far above the runaway threshold, of metals with high self-sputtering yield (here copper, zinc, bismuth) is well suited to supply ions for extraction and beam formation. This is the basis for a new ion source: a self-sputtering ion source. Even as the discharge pulses are conveniently initiated through the presence of gas, the gas component is very small because self-sputtering is driven far above the self-sputtering threshold such that the plasma becomes completely dominated by metal ions. The transition to sustained self-sputtering is completed typical within $50 \mu$ s after current onset, and this implies that long pulses of $100 \mu$ s or longer are preferable. Through timeof-flight spectrometry it was shown that singly charged metal ions exceed by far any other ion species. This is in contrast to vacuum arc ion sources, which are noisy and contain multiply charge states. The relative charge state purity can be ascribed to annihilation of doubly or higher charged ions through non-resonant charge exchange reactions, followed by diffusion which is facilitated by resonant charge exchange collisions. This concept was demonstrated for $\mathrm{Cu}, \mathrm{Zn}$, and $\mathrm{Bi}$, and the highest ion beam current obtained was $300 \mathrm{~mA}$ of $\mathrm{Cu}^{+}$at an extraction voltage of $45 \mathrm{kV}$, which approximately corresponds to the Child limit of the extraction system used.

\section{ACKNOWLEDGMENTS}


This work was supported by the U.S. Department of Energy, Initiatives for Proliferation Prevention, under Contract No. DE-AC02-05CH11231. 


\section{REFERENCES}

1 The Physics and Technology of Ion Sources; edited by I. G. Brown (Wiley-VCH, Weinheim, 2004).

2 A. Anders, Phys. Rev. E 55, 969 (1997).

3 A. Anders, Cathodic Arcs: From Fractal Spots to Energetic Condensation (Springer, New York, 2008).

4 A. T. Forrester, Large Ion Beams (Wiley, New York, 1988).

5 J. W. Kwan, A. Anders, F. M. Bieniosek, E. Chacon-Golcher, E. Henestroza, K. N.

Leung, L. A. Ahle, D. P. Grote, and A. W. Molvik, Rev. Sci. Instrum. 73, 1084 (2002).

6 V. Kouznetsov, K. Macak, J. M. Schneider, U. Helmersson, and I. Petrov, Surf. Coat. Technol. 122, 290 (1999).

7 K. Macak, V. Kouznetsov, J. Schneider, U. Helmersson, and I. Petrov, J. Vac. Sci. Technol. A 18, 1533 (2000).

8 J. Vlček, P. Kudláček, K. Burcalová, and J. Musil, Eur. Phys. Lett. 77, 45002 (2007).

9 J. Andersson and A. Anders, Phys. Rev. Lett. 102, 045003 (2009).

10 W. M. Posadowski and Z. Radzimski, J. Vac. Sci. Technol. A 11, 2980 (1993).

11 N. Hosokawa, T. Tsukada, and H. Kitahara, Effect of discharge current and sustained self-sputtering, Proc. 8th Int. Vacuum Congress, Le Vide, Cannes, France, 11-14 (1980).

12 A. Anders, J. Andersson, and A. Ehiasarian, J. Appl. Phys. 102, 113303 (2007).

13 U. Helmersson, M. Lattemann, J. Bohlmark, A. P. Ehiasarian, and J. T. Gudmundsson, Thin Solid Films 513, 1 (2006). 
14 A. Anders, J. Andersson, and A. Ehiasarian, J. Appl. Phys. 103, 039901 (2008).

15 P. Kudláček, J. Vlček, K. Burcalová, and J. Lukáš, Plasma Sources Sci. Technol. 17, 025010 (2008).

16 A. Anders, Appl. Phys. Lett. 92, 201501 (2008).

17 H. Eder, W. Messerschmidt, H. Winter, and F. Aumayr, J. Appl. Phys. 87, 8198 (2000).

18 R. A. Baragiola, E. V. Alonso, J. Ferron, and A. Oliva-Florio, Surf. Sci. 90, 240 (1979).

19 Handbook of Chemistry and Physics, $81^{\text {st }}$ Edition; edited by D. R. Lide (CRC Press, Boca Raton, New York, 2000).

20 Y. Nakai, T. Shirai, T. Tabata, and R. Ito, Physica Scripta T28, 77 (1989).

21 B. M. Smirnov, Plasma Processes and Plasma Kinetics (Wiley-VCH, Weinheim, Germany, 2007).

22 G. Lubinski, Z. Juhász, R. Morgenstern, and R. Hoekstra, Phys. Rev. Lett. 86, 616 (2001).

23 J. F. Ziegler and J. Biersack, "Monte Carlo code SRIM2006.02, downloadable from http://srim.org/," (2006).

24 S. M. Rossnagel, J. Vacuum Sci. Technol. B 16, 3008 (1998).

25 Ionized Physical Vapor Deposition; edited by J. A. Hopwood (Academic Press, San Diego, CA, 2000).

26 B. M. Smirnov, Physica Scripta 61, 595 (2000)

27 E. Oks and A. Anders, J. Appl. Phys. 105, 093304 (2009). 
I. G. Brown, J. E. Galvin, R. A. MacGill, and R. T. Wright, Rev. Sci. Instrum 58, 1589 (1987).

29 J. Andersson and A. Anders, Appl. Phys. Lett. 92, 221503 (2008).

30 I. G. Brown, Rev. Sci. Instrum. 65, 3061 (1994).

31 A. Anders, E. M. Oks, and G. Yu.Yushkov, Appl. Phys. Lett. 86, 211503 (2005).

32 E. M. Oks, A. Anders, I. G. Brown, M. R. Dickinson, and R. A. MacGill, IEEE

Trans. Plasma Sci. 24, 1174 (1996).

33 M. Keidar, I. I. Beilis, R. L. Boxman, and S. Goldsmith, IEEE Trans. Plasma Sci. 25, 580 (1997).

34 A. Anders and E. Oks, J. Appl. Phys. 99, 103301 (2006). 


\section{TABLES}

Table I. First and second ionization energies ${ }^{19}$, energy defect for charge exchange of type (6), and cross section for resonant charge exchange of metals used in this study: $\mathrm{Cu}, \mathrm{Zn}$, and $\mathrm{Bi}\left(\mathrm{from}^{26}\right)$.

\begin{tabular}{lcccl}
\hline target & $E_{0 \rightarrow 1}$, & $E_{1 \rightarrow 2}$, & $\Delta E$, & $\sigma_{\text {res }}$, \\
material & $(\mathrm{eV})$ & $(\mathrm{eV})$ & $(\mathrm{eV})$ & $\left(10^{-18} \mathrm{~m}^{-2}\right)$ \\
\hline $\mathrm{Cu}$ & 7.73 & 20.29 & 12.56 & 1.5 \\
$\mathrm{Zn}$ & 9.39 & 17.96 & 8.57 & 1.1 \\
$\mathrm{Bi}$ & 7.29 & 16.69 & 9.40 & 2.0 \\
\hline
\end{tabular}




\section{FIGURE CAPTIONS}

Fig. 1 Magnetron discharge and ion beam current pulses as a function of time; copper target, the ion beam current was monitored by the $20 \mathrm{~cm}^{2} \mathrm{FC}$ on axis $0.5 \mathrm{~m}$ from the extractor grid, extraction voltage $40 \mathrm{kV}$.

Fig. 2 Ion beam profile $0.5 \mathrm{~m}$ downstream after extraction as measured with the small FC moving in steps perpendicular to the beam direction; the steady state discharge current was $60 \mathrm{~A}$, with an initial gas pressure of about $0.2 \mathrm{~Pa}$ nitrogen in the source region.

Fig. 3 Time-of-flight spectrum of a copper beam [(a) and (b)], and a bismuth beam [(c) and (d)], measured $25 \mu \mathrm{s}[(\mathrm{a})$ and (c)] and $150 \mu \mathrm{s}$ [(b) and (d)] after the current pulse started.

Fig. 4 Pulse discharge in which arcing occurred halfway through the pulse: the burning voltage, as measured between cathode (target) and anode (ground) drops sharply, while the discharge current increases. The upper curve shows the copper ion beam current as measured with the $20 \mathrm{~cm}^{2}$ Faraday cup. This pulse illustrates the ion source quality when based on self-sputtering plasma (first half), in comparison to a vacuum arc (second half of the pulse). 


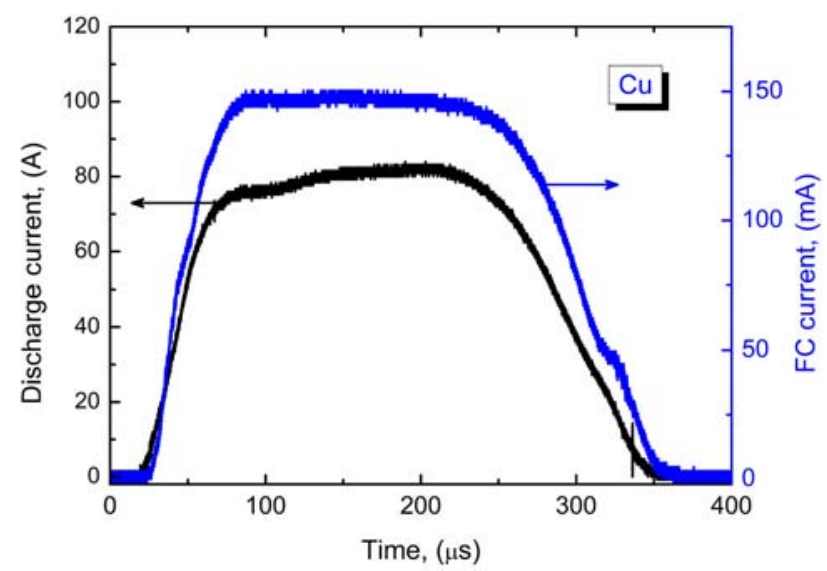

Fig. 1 


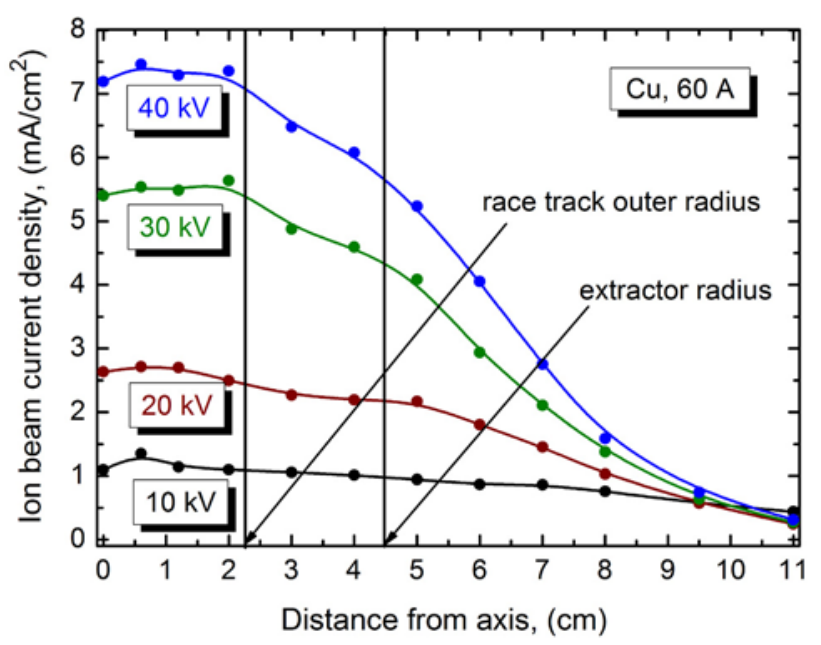

Fig. 2 

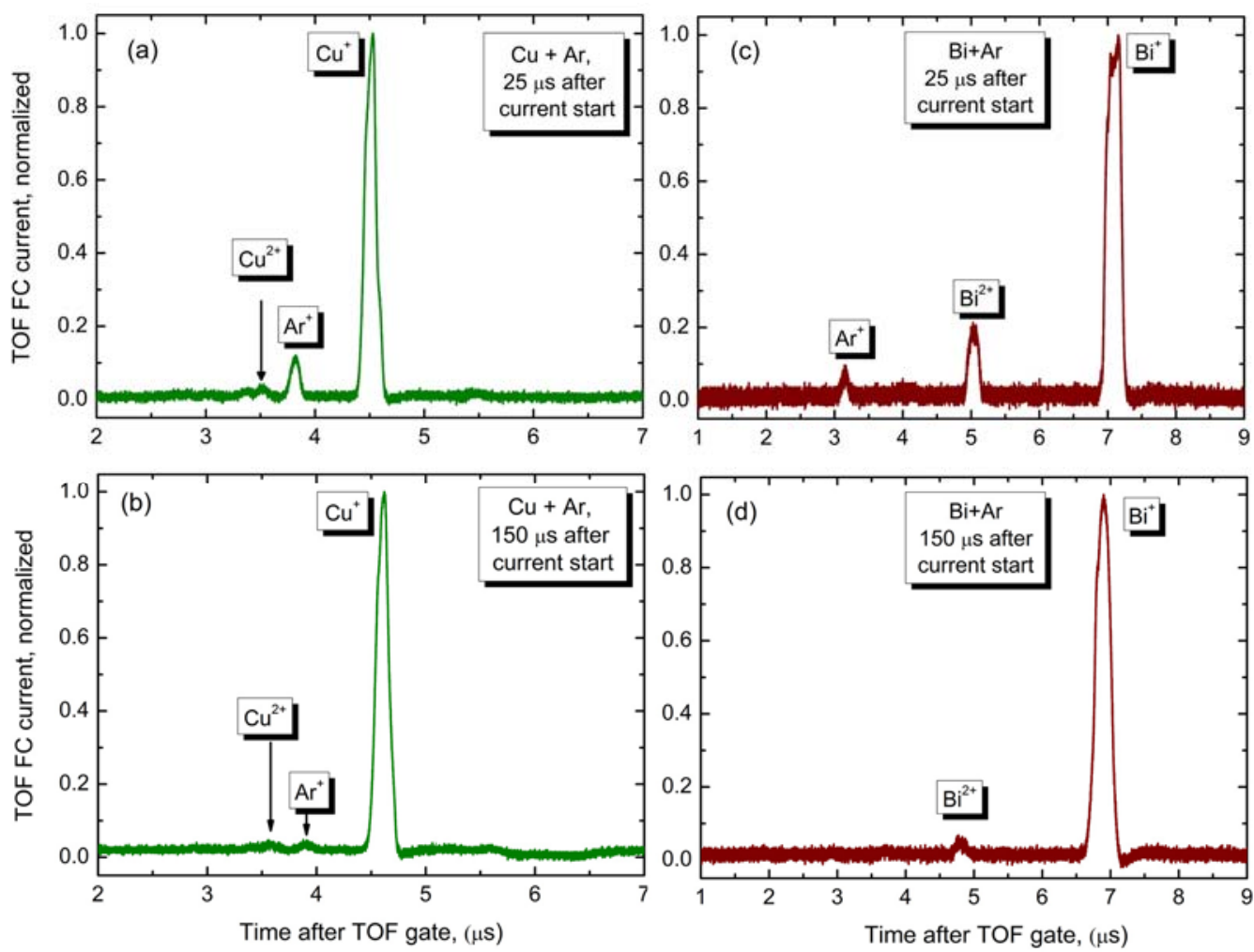

Fig. 3 


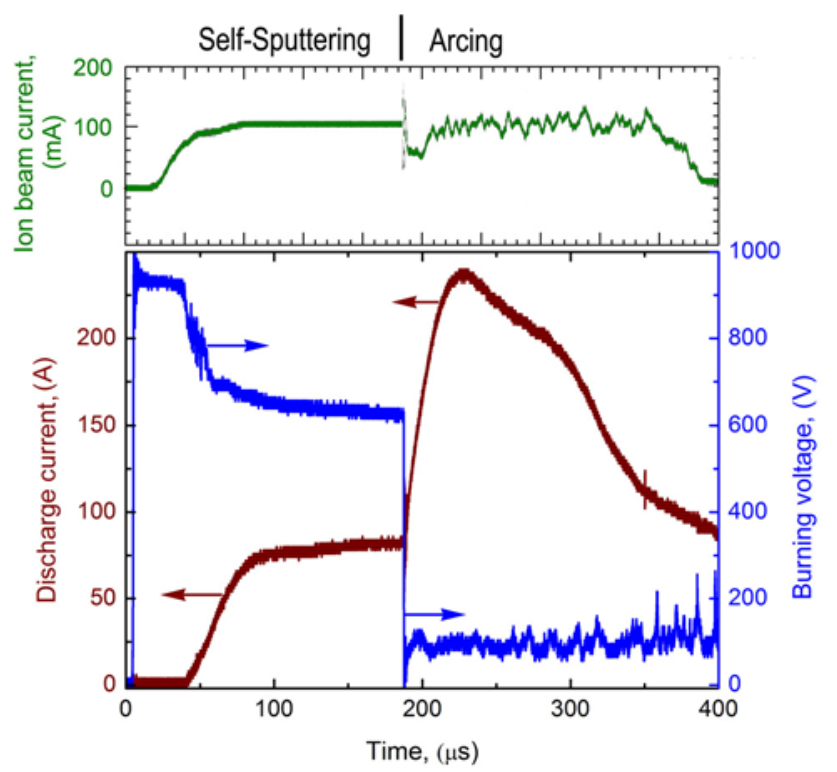

Fig. 4 